\title{
The tight esophagus - Bougies or balloons
}

\author{
JOHN S GOFF, MD
}

\begin{abstract}
Esophageal strictures can be managed with a variety of techniques. Each device for dilation has its advantages and disadvantages which are important in selecting the appropriate one for each situation. Stricture management with dilation may require many sessions over a prolonged time. Complications of dilation are infrequent, but perforation must be watched for closely since its consequences are so serious. The most important factor in stricture management with dilators is physician familiarity with the method selected. Can J Gastroenterol 1990;4(9):593-595
\end{abstract}

Key Words: Dilation, Esophageal stricture

\section{La sténose de l'oesophage - Bougies ou ballons}

RESUME: Les rétrécissements de l'oesophage peuvent être traités par diverses techniques. Chaque instrument servant à la dilatation a ses avantages et ses inconvénients, qui sont à prendre en considération au moment de choisir la so'ution adaptée à chaque situation. Le traitement peut requérir des dilatations répétées sur une période prolongée. Les complications de la dilatation sont peu fréquentes mais il faut rester attentif à toute perforation éventuelle, les conséquences étant particulièrement graves. Le facteur le plus important dans le traitement des sténoses au dilatateur est la dextérité du médecin pour la méthode choisie.

E SOPHAGEAL NARROWING WHICH causes dysphagia can usually be treated by dilation with a variety of techniques. Narrowings that are potentially treatable include peptic, neoplastic, corrosive, anastomotic, radiation and post sclerotherapy strictures, plus rings, webs, diffuse esophageal spasm, cricopharyngeal achalasia and achalasia. These lesions should be diagnosed by barium radiography, endoscopy and manometry used singly or in combination before treatment is undertaken. In the treatment plan, esophageal dilation is only a portion of the care and should be individualized for each disorder and patient.
A variety of dilating devices are available to the physician for stretching an esophageal narrowing. The EderPuestow technique employs metal olives that are passed over a guidewire (Figure 1).

Mercury-filled rubber bougies come with either a taper tip (Maloney; Pilling, Pennsylvania) or a blunt tip (Hurst; Pilling, Pennsylvania) (Figure 2). The Celestin dilator is usually passed over a guidewire and has several graded diameters per dilator, while the Savary (Wilson-Cook Medical, North Carolina) and Savary-like tapered dilators are each a different size (Figure

University of Colorado Medical Center and Denver Veterans Administration Hospital, Denver, Colorado, USA

Correspondence and reprints: Dr JS Goff, 4200 E 9th Avenue, B158, Denver, CO 80262 , USA. Telephone (303) 270-7131

2). Gruntzig (Microvasive, Massachusetts) balloon dilators can be used solely over a guidewire, over a guidewire alongside an endoscope, or purely through the endoscope (Figure 3).

The choice of method is difficult. The Eder-Puestow (Eder Instruments, Illinois) technique has been used for a long time, but the instrument is somewhat difficult for the patient to tolerate and the outcome tends to be splitting of the esophageal lesion rather than stretching it (1). This technique requires multiple passes through the pharynx over a guidewire. The flexible metal shaft of the dilator can traumatize the pharynx. The olives that are changed with each passage are short and fat, which is a distinctly disadvantageous shape for dilation of an esophageal stricture. The lack of taper on the olive (wide angle of incidence) means that there is considerable axial instead of radial force delivered to the stricture. Thus, the risk of tearing is higher. Also, the length of the point of maximal diameter on the olive is very short, which is undesirable for long strictures.

Effective stretching can be achieved by use of any of the tapered dilating systems. Mercury bougies are less effective than polyvinyl dilators at small sizes because they are too flimsy. Tapered-tip mercury-filled soft rubber dilators are most commonly used for simple benign esophageal strictures. Blunt mercury-filled bougies (Hurst; Pilling, Pennsylvania) are best for disruption of esophageal rings and webs. The flexibility of the mercury-filled bougie adds a degree of safety since it will bend more easily. This allows for 


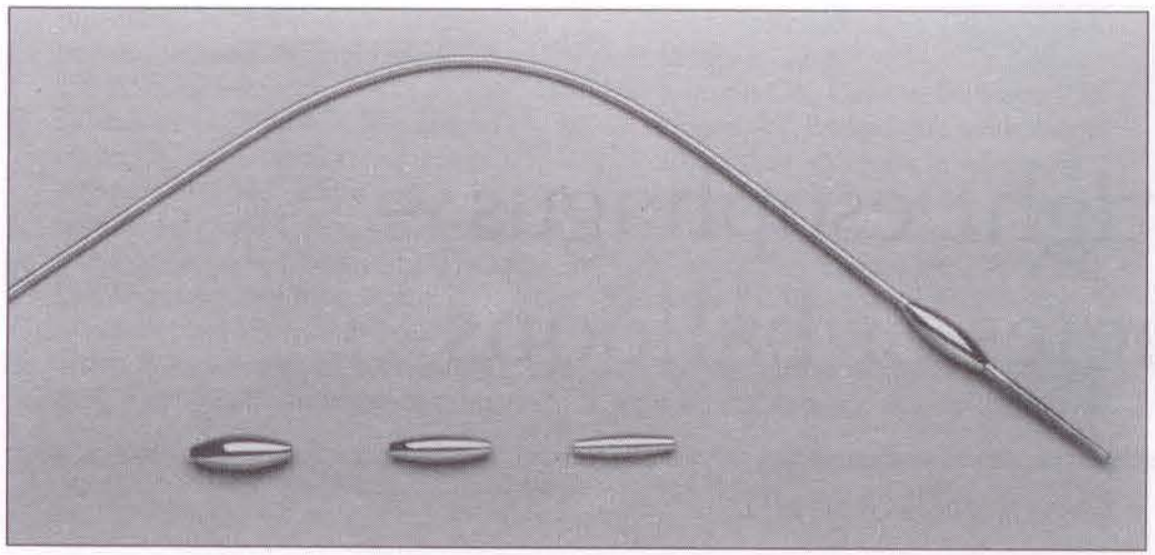

Figure 1) Eder-Puestow dilator shown with interchangeable metal olives. The very flexible spring tip precedes the olive and the more rigid pushing shaft over the guidewire (not shown) into the esophagus and stomach

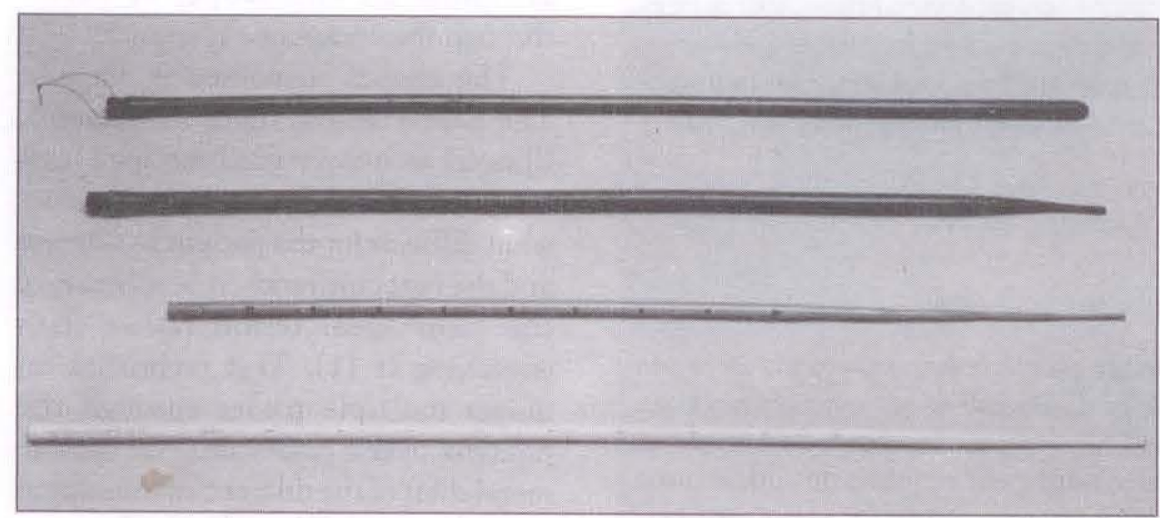

Figure 2) Bougies or dilators. The top two are rubber and filled with mercury. The blunt-tipped mercury-filled dilator is a Hurst dilator and the taper-tipped one is a Maloney. The third dilator from the top is a Celestin dilator, which passes over a guidewire (not shown) and has four separate dilating segments each a bit larger than the preceding one. The bottom dilator is a polyvinyl taper-tipped dilator primarily designed to be passed over a guidewire, although it can be used cautiously without

safer passage through the pharynx and may make perforation less likely, since the bougie will flex when pushed against an obstructing surface. The disadvantage, as mentioned above, is the lack of creation of any stretching force with the small diameter bougies. They easily buckle in the esophagus, which can give the physician the false sense of effectively dilating the stricture. Larger bougies can also buckle, and if the physician is not familiar with the feel of the difference between stretching a stricture and buckling in the esophageal lumen, he or she may push too hard and rupture the esophageal wall with the bowed dilator.

Long, tortuous and very tight narrowings are best treated over an endoscopically or fluoroscopically placed increasing diameter (Figure 2), which generally means the physician has to pass at most, two dilators to achieve effective dilation; however, the length of the dilator may create problems in patients with small stomachs. For the uncomplicated stricture, polyvinyl tapered dilators can be used without the guidewire only if the treating physician is very familiar with the patient and his or her stricture.

Balloon dilators offer a different method for stretching the esophagus $(5,6)$. Balloons produce a radial dilating force with no shearing force (axial) as is produced by the tapered dilators. This 'radial only' force should in theory be more effective with fewer complications.

Balloon dilation must always be done under fluoroscopic or endoscopic guidance. The new through-the-scope balloons are the easiest to use and allow for repeated dilations at one setting without multiple passages through the oropharynx. Also, one can immediately assess the response to the dilation, since it can be viewed through the endo. scope. Whether balloons are better than bougies in relieving dysphagia remains a controversial issue. At least one study has suggested that the bal. loons are inferior to bougies. Cox et al (5) have found that the dysphagia score improved more in patients receiving a bougie rather than pneumatic balloon dilation, and that the stricture's post dilation diameter was greater over time in the bougie group even though the intent was to achieve equal stricture diameters after treatment with both methods. Drawbacks to the balloon sys. tem are the cost of and much shorter life span of balloons versus bougies.

Esophageal dilation should be performed on fasted patients. Most patients will require some topical pharyngeal anesthesia. Parenteral anal. gesics or sedatives may be used but are not necessary for most simple dilations, especially if they are repeat (main. tenance) procedures. The patient is kept in the sitting position for dilation with the mercury-filled bougies, while the left lateral decubitus or supine positions are best for guidewire- or endo. scope-guided dilations.

Fluoroscopy may be used to assist in 


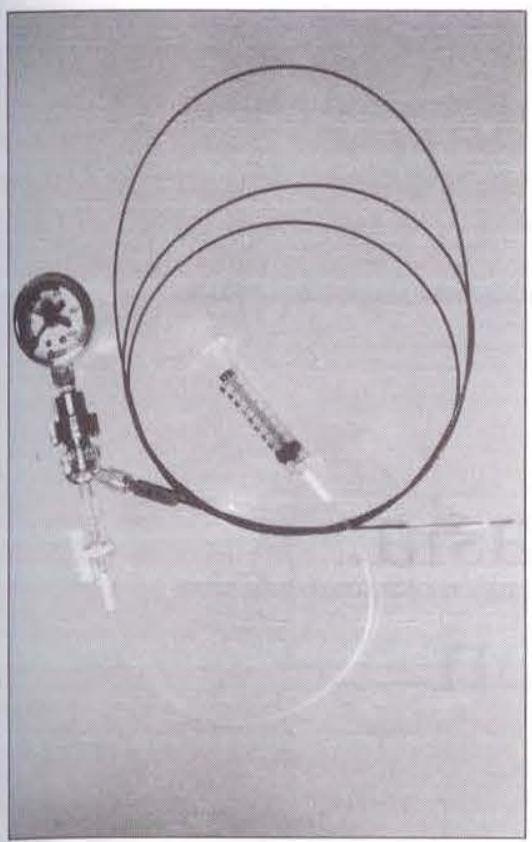

Figure 3) Microvasive through-the-scope balloon dilator. The catheter has a soft, flexible tip and is stiffened throughout with a built in guidewire. The balloon is inflated to the desired pressure, which is monitored by the pressure gauge once the balloon is positioned within the stricture lumen

the correct performance of an esophageal dilation, but is used less today with the increased use of the endoscope either to place the guidewire or to place the balloon dilator directly. Any difficult stricture can be more safely dilated with the aid of fluoroscopy no matter which system is being used. The added visual dimension of fluoroscopy will help prevent perforation from misdirected dilators, dilators passed too far into the stomach, or excessively bowed

\section{REFERENCES}

1. Rago E, Boesby S, Spencer J. Results of Eder-Puestow dilatation in the management of esophageal peptic strictures. Am J Gastroenterol 1983;78:6-8.

2. Dumon J-F, Meric B, Sivak MV, Fleischer D. A new method of esophageal dilatation using Savory-Gilliard bougies. Gastrointest Endosc 1985;31:379-82.

3. Celestin LR, Campbell WB. A new and safe system for oesophageal dilatation. Lancet 1981;i:74-5.

4. Hine KR, Hawkey CJ, Atkinson M, Holmes GKT. Comparison of the EderPuestow and Celestin techniques for dilating benign oesophageal strictures. dilators (7). Fluoroscopy also allows the physician to assess whether a balloon dilator has fully expanded or not when it is inflated in a stricture.

The choice of the initial dilator size should be based on an estimated diameter of the narrowing by either prior barium swallow or endoscopy. Ideally, one should try to achieve a final esophageal lumen diameter of between 40 and 50 French. This diameter is recommended since symptomatic deterioration seems to recur less quickly after these larger diameters have been reached $(8-10)$. The final desired diameter may not be reached at the initial session because of pain or excessive blood on the dilators.

No specific testing needs to be performed on the patient after an uneventful dilation; however, if there is any suspicion that perforation has occurred, a water-soluble contrast esophagram should be done immediately. This is followed by a barium esophagram if no leak is seen, since barium may show a leak not seen with water-soluble contrast. It is very important to do these studies at the first suspicion of a perforation; every minute is critical in the management of esophageal perforation; (surgery in the first few hours is easier, more effective, and associated with fewer complications than a delayed operation).

Rupturing of rings and webs with a large (greater than 48 French) blunt bougie will usually take care of the problem in one session, though occasionally they may recur. Dilation of malignant strictures requires frequent repetition

\section{Gut 1984;25:1100-02}

5. Cox JGC, Winter RK, Maslin SC, et al. Balloon or bougie for dilatation of benign oesophageal stricture? An interim report of a randomised controlled trial. Gut 1988;29:1741-7.

6. Kozarek RA. Hydrostatic balloon dilation of gastrointestinal stenoses: A national survey, Gastrointest Endosc 1986;32:15-9.

7. Tulman AB, Boyce HW. Complications of esophageal dilation and guidelines for their prevention. Gastrointest Endosc 1981;27:229-34.

8. Patterson DJ, Graham DY, Smith JL, et al. Natural history of benign unless the cancer is treated with radiation, chemotherapy, laser therapy or a combination. Benign reflux-related esophageal strictures may respond to a single dilation and vigorous antireflux measures; often, however, these strictures require frequent or repeated dilations, unless they are treated by vigorous intraoperative dilation and a Nissen fundoplication. Up to $50 \%$ of patients with moderate to severe strictures will require multiple dilations over one or more years to control their dysphagia $(8-10)$. Lye-induced strictures are notoriously difficult to treat and often require repeated dilations for many years. Patients who have frequently recurring strictures may be taught to self-dilate at home.

The main complications encountered after esophageal dilation are perforation, bleeding, and aspiration pneumonia. The frequency of these complications ranges from 0.3 to $1.0 \%$ (7). Bacteremia during and after esophageal dilation has been reported in five to $100 \%$ of patients studied (11). Consequently, one must consider antibiotic prophylaxis for patients with increased risk of endocarditis.

Esophageal dilation is a safe and effective method for relieving dysphagia secondary to mechanical narrowing of the esophageal lumen. Given the array of dilators available, one should be able to manage any narrowing using one device or another alone or in combination. However, the potential for serious complications is very high if the operator is not experienced in the use of these instruments.

esophageal stricture treated by dilatation. Gastroenterology 1983;85:346-50.

9. Ogilvie AL, Ferguson R, Atkinson M. Outlook with conservative treatment of peptic oesophageal stricture. Gut 1980;21:23-5.

10. Wesdrop ICE, Bartelsman JFWM, den Hartog Jager FCA, et al. Results of conservative treatment of benign esophageal strictures: A follow-up study in 100 patients. Gastroenterology 1982;82:487-93.

11. Raines DR, Branch WC, Anderson DI, Boyce HW. The occurrence of bacteremia after esophageal dilation. Gastrointest Endosc 1975;22:86-9. 


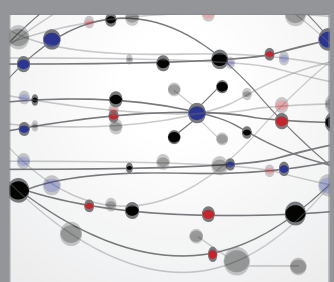

The Scientific World Journal
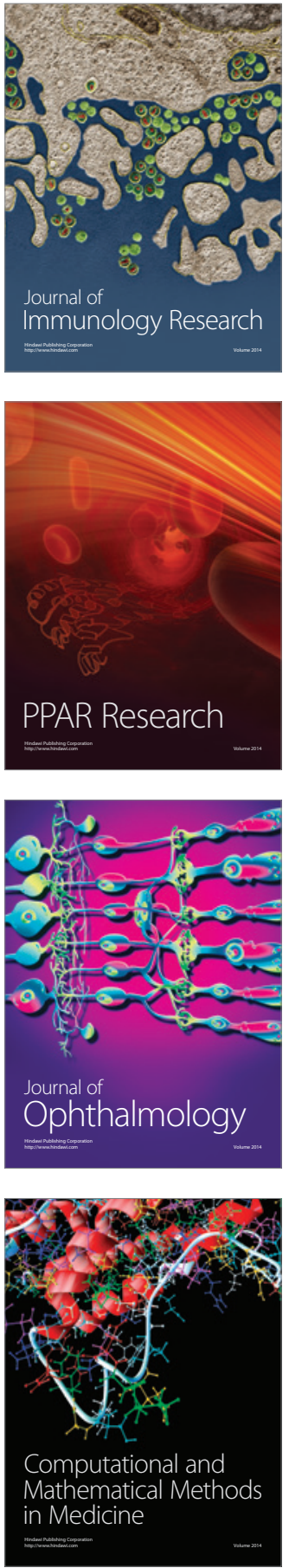

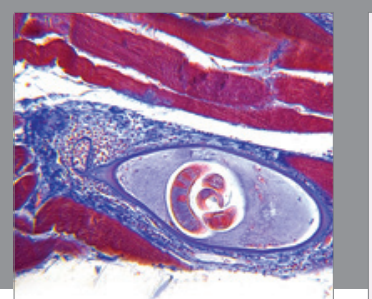

Gastroenterology Research and Practice

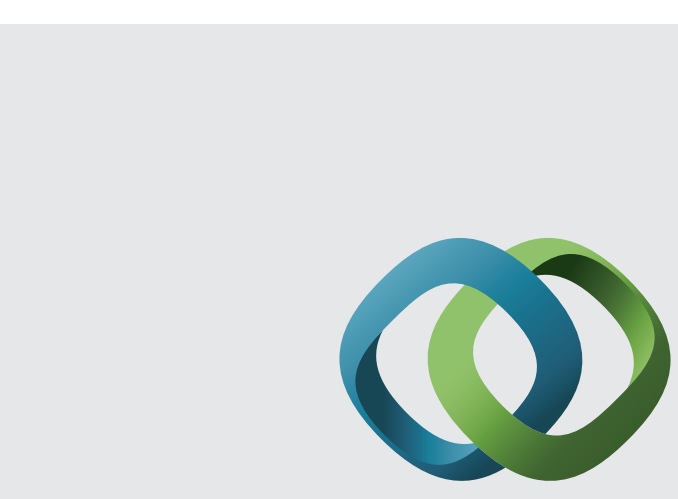

\section{Hindawi}

Submit your manuscripts at

http://www.hindawi.com
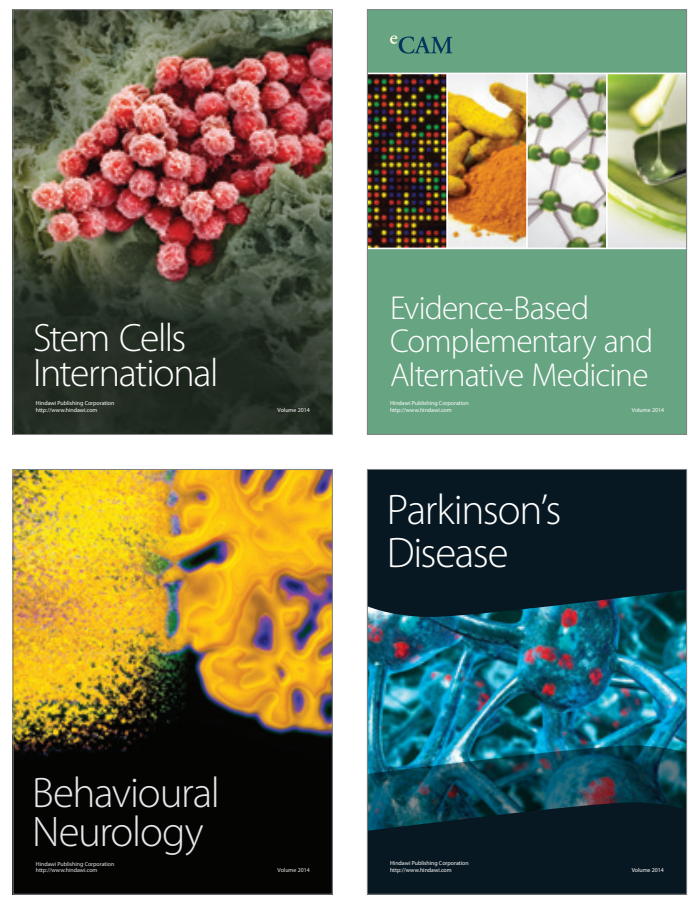
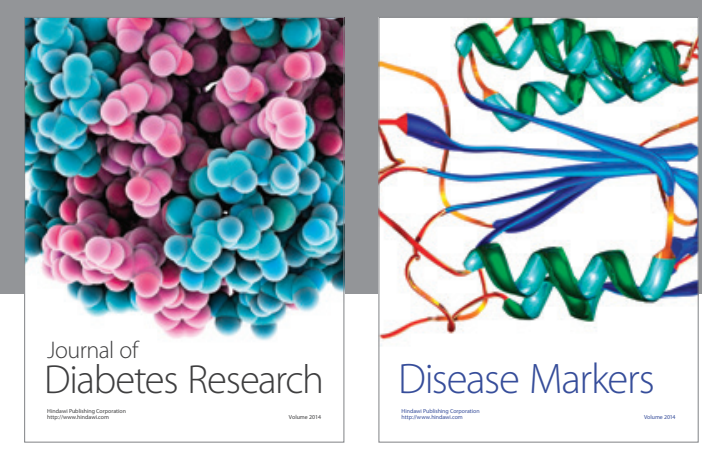

Disease Markers
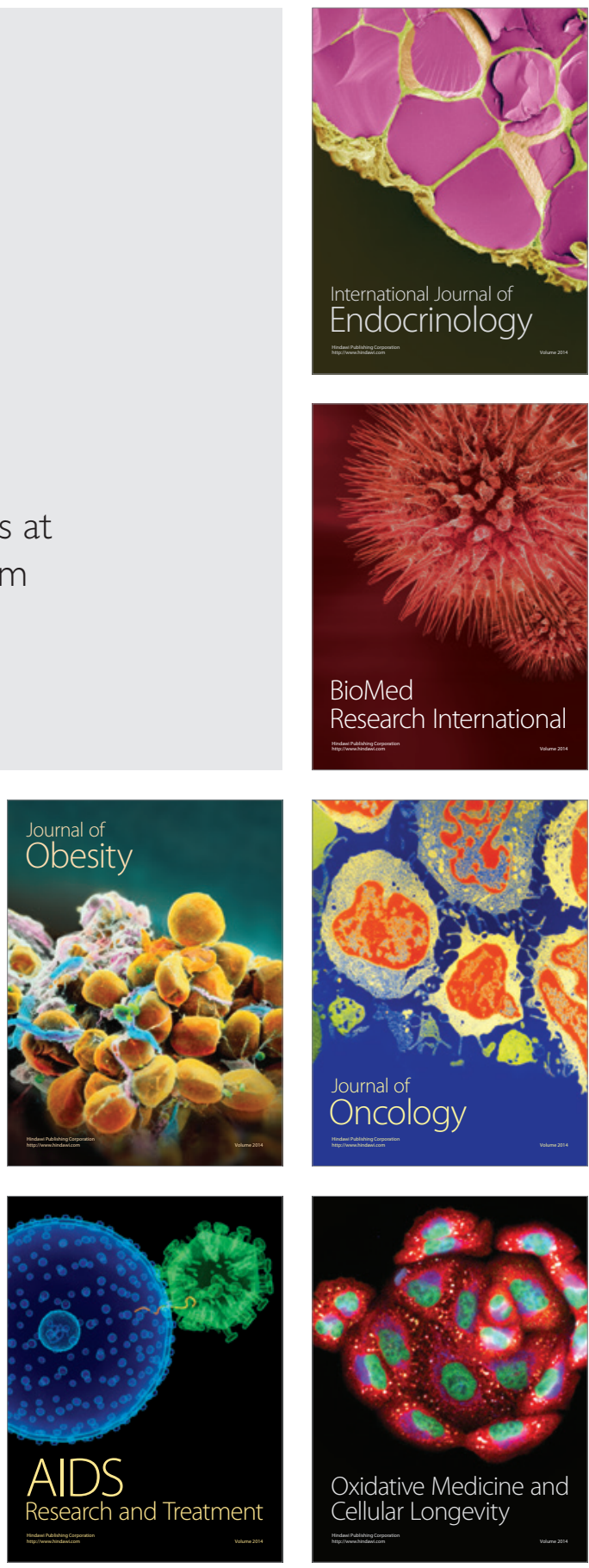